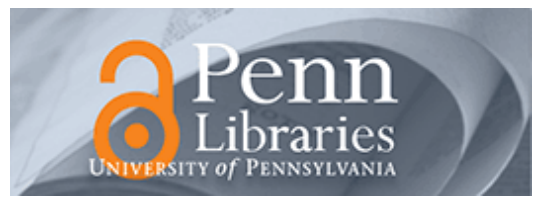

University of Pennsylvania

ScholarlyCommons

Finance Papers

Wharton Faculty Research

4-1996

\title{
Stochastic Regime Switching and Stabilizing Policies within Regimes
}

Karen K. Lewis

University of Pennsylvania

Follow this and additional works at: https://repository.upenn.edu/fnce_papers

Part of the Economics Commons, and the Finance and Financial Management Commons

\section{Recommended Citation}

Lewis, K. K. (1996). Stochastic Regime Switching and Stabilizing Policies within Regimes. International Journal of Finance \& Economics, 1 (2), 71-85. http://dx.doi.org/ 10.1002/(SICI)1099-1158(199604)1:2<71::AID-IJFE7>3.0.CO;2-T

This paper is posted at ScholarlyCommons. https://repository.upenn.edu/fnce_papers/173

For more information, please contact repository@pobox.upenn.edu. 


\title{
Stochastic Regime Switching and Stabilizing Policies within Regimes
}

\begin{abstract}
This paper describes a class of stochastic stabilizing policies within asset price regimes; that can be easily incorporated into the framework of regime swtiching recently proposed by $\mathrm{K}$. A. Froot and $\mathrm{M}$. Obstfeld. In contrast to previous treatments of market-driven fundamentals within the regime, authorities stochasstically counteract movements in these fundamentals before asset prices reach boundary points. This paper describes how the stabilizing intra-regime intervention policies can be used to characterize the behaviour of monetary authorities before fixing an exchange rate, as in the cases studied by R. P. Flood and P. Garber. An intervention policy within target zone bands consistent with empirical evidence is also a member of this class of policies. Furthermore, the stylized features of these intervention policies may be matched to actual data in a natural way.
\end{abstract}

Disciplines

Economics | Finance and Financial Management 


\title{
STOCHASTIC REGIME SWITCHING \\ AND STABILIZING POLICIES \\ WITHIN REGIMES
}

\author{
Karen K. Lewis
}

Working Paper 5289

\section{NATIONAL BUREAU OF ECONOMIC RESEARCH 1050 Massachusetts Avenue \\ Cambridge, MA 02138 \\ October 1995}

This paper is part of NBER's research programs in Asset Pricing and International Finance and Macroeconomics. Any opinions expressed are those of the author and not those of the National Bureau of Economic Research.

(C) 1995 by Karen K. Lewis. All rights reserved. Short sections of text, not to exceed two paragraphs, may be quoted without explicit permission provided that full credit, including $(\mathcal{O}$ notice, is given to the source. 


\title{
STOCHASTIC REGIME SWITCHING \\ AND STABILIZING POLICIES \\ WITHIN REGIMES
}

\begin{abstract}
This paper describes a class of stochastic stabilizing policies within asset price regimes that can be easily incorporated into the framework of regime switching recently proposed by Froot and Obstfeld (1991). In contrast to previous treatments of market-driven fundamentals within the regime, authorities stochastically counteract movements in these fundamentals before asset prices reach boundary points. The paper describes how the stabilizing intra-regime intervention policies can be used to characterize the behavior of monetary authorities before fixing an exchange rate, as in the case studied by Flood and Garber (1983). An intervention policy within target zone bands consistent with empirical evidence is also a member of this class of policies. Furthermore, the stylized features of these intervention policies may be matched to actual data in a natural way.
\end{abstract}

Karen K. Lewis

Department of Finance, 2300 SH-DH

The Wharton School

University of Pennsylvania

Philadelphia, PA 19104-6367

and NBER 
Economists have recently begun to examine the effects of prospective shifts in policy regimes upon forward looking variables. Froot and Obstfeld (1991a) demonstrate how a general continuous time framework can be incorporated to yield tractable solutions. Using this framework, they provide a simple and intuitive solution to the problem studied by Flood and Garber (1983) of Britain's return to a gold standard. $1 /$ Another regime that can be examined within this framework is the policy of targeting exchange rates or interest rates within given bands. $2 /$ Examples of band-type regimes are the current European Monetary System, the system of managed float instituted by the Louvre Accord in 1987, and the U.S. policy of targeting interest rates in the 1970's. $\underline{3} /$

The solutions found by Froot and Obstfeld (1991a) are particularly simple when the determinants of the asset prices are assumed to follow Brownian motion. In the case of the return to a fixed exchange rate regime, this assumption implies that the monetary authorities allowed the exchange rate to fluctuate freely until hitting the pre-war level. In the case of bands on targeted variables, it is assumed that the authorities do not intervene until the exchange rate hits the target band. The tractability implied by these assumptions have contributed to their widespread acceptance.

The acceptance of the tractability assumption that asset price determinants follow Brownian motion within regimes can lead to incorrect interpretations of observed asset price behavior, however. For example, when authorities target exchange rates or interest rates within bands, they often intervene to keep rates from reaching the bands. Thus, even if market-determined fundamentals followed Brownian motion, intervention by monetary authorities would distort this process. The combined effects of market fundamentals and

\footnotetext{
1/ For another solution to this problem, see also Smith (1991).

2/ See Froot and Obstfeld (1991b).

$\underline{3} /$ On exchange rate target zones, see Froot and Obstfeld (1991b), Flood and Garber (1989), and Krugman (1991), among many others. On the U.S. policy of targeting interest rates, see Cook and Hahn (1989).
} 
intervention therefore imply different exchange rate behavior within the regime. Similarly, historical accounts of Britain's return to gold suggest that British authorities did not allow free gold movements before the return. Rather, in the period before the return to gold, capital flows were restricted and private holdings of gold were discouraged in an attempt to stabilize exchange rate movements. 4 /

In this paper, I describe a class of discrete time intra-regime policies that can be approximated by continuous time diffusion processes. These continuous time processes allow for simple solutions as in the Froot and Obstfeld (1991a) framework. In addition, these characterizations of policy have several advantages over alternatives in the literature. First, the class of policies takes as given that market-determined fundamentals follow Brownian motion. The intervention policy simply distorts the evolution of market fundamentals. This treatment allows for an easy comparison of the standard literature with Brownian motion fundamentals. 5 / Second, the implications of these policies provide realistic distributions for both fundamentals and asset prices. For example, while intraregime Brownian motion for fundamentals implies that exchange rates within target bands should have bi-modal distributions concentrated at the bands, empirical evidence has shown that they tend to be unimodal and concentrated near the middle of the band.6/ Third, the solutions obtained with this class of intra-regime policies provide stylized features that can easily be related to intervention data where the magnitudes are frequently unobserved. For example, controls before returning to a fixed rate may prevent capital flows. In the presence of capital controls, these magnitudes of the flows are unobserved. With stylized

4/ See Moggridge (1972) and Yeager (1976).

5/ Studies that consider processes for fundamentals other than Brownian motion include Delgado and Dumas (1991) and Froot and Obstfeld (1991a).

6/ Svensson (1991) pointed out the implied asymptotic distribution of exchange rates within target bands. Subsequently, Bertola and Caballero (1992) and Flood, Rose, and Mathieson (1991) have demonstrated that this implication is counterfactual in the case of the European Monetary System. 
forms of intra-regime intervention as described below, these magnitudes may be treated as unobserved latent variables, and can be incorporated into empirical studies in a straightforward manner.

The plan of the paper is as follows. Section 2 describes the standard asset pricing model in the presence of regimes when intra-regime intervention is assumed to follow Brownian motion. Section 3 describes the regime switch to a permanent fix. Capital flow restrictions and other interventions are imposed with greater frequency as the exchange rate nears the fix parity. Section 4 describes the regime where asset prices are reflected within bands. Interventions attempt to stop movements in asset prices away from targetted levels and hence away from the bands. Section 5 describes empirical applications of both cases as well as extensions to other regimes.

\section{The Asset Pricing Model With No Intra-Regime Intervention}

To illustrate the importance of intra-regime intervention, I begin with a brief summary of the standard model without intra-regime intervention. For the purpose of illustration, I will follow the notation and methodology of Froot and Obstfeld (1991a) in this section.

The logarithm of the spot exchange rate at time $t, x(t)$, depends upon a linear combination of macroeconomic fundamentals summarized by the scalar, $k(t)$, and the expected change in the spot exchange rate:

(l) $x(t)=k(t)+\alpha E\{d x(t)\} \Omega(t)\} / d t$. 
In (1), $\alpha$ measures the rate at which traders discount the future. In monetary models, this parameter is the semi-elasticity of money demand. $7 / E\{\mid \Omega(t)\}$ is the expectations operator conditional upon information available at time $t$, defined as $\Omega(\mathrm{t})$.

In a rational expectations equilibrium (with no speculative bubbles), the solution to this equation is given by:

(2) $x(t)=\alpha^{-1} \int_{t}^{\infty} e^{(t-s) / \alpha} E\{k(s) \mid \Omega(t)\} d s$.

Thus, equation (2) says that the current exchange rate depends upon the expected future path of its determinants, summarized in $\mathrm{k}(\mathrm{t})$, where the information in $\Omega$ includes both the process of market-determined fundamentals and the policy regime followed by the authorities. In other words, to determine the exchange rate, traders condition their expectations of future fundamentals upon (a) the movements of fundamentals within the boundaries of the regimes, and (b) the behavior of the authorities at the boundaries. For future reference, I will call behavior within the boundaries "intra-regime" and behavior at the boundaries "regime".

An intra-regime process that provides tractable solutions is:

(3) $\mathrm{dk}(\mathrm{t})=\mu \mathrm{dt}+\sigma \mathrm{dz}(\mathrm{t})$

where $\mu$ is the deterministic drift of $\mathrm{k}, \mathrm{dz}$ is a standard Wiener process, and $\sigma^{2}$ is the variance of $k$.

I/ See Mussa (1982), for example. 
To get the solution subject to boundary conditions, I first assume that the family of solutions that solve (2) conditional on (3) can be written as a twice-differentiable function $\mathbf{x}$ $=G(k)$. Then applying Ito's Lemma to (3) to solve for $E(d x \mid W)$ in (1), this family of functions can be written:

(4) $\mathrm{G}(\mathrm{k})=\mathrm{k}+\alpha \mu \mathrm{G}^{\prime}(\mathrm{k})+\left(\alpha \sigma^{2} / 2\right) \mathrm{G}^{\prime \prime}(\mathrm{k})$.

Equation (4) is an ordinary second order differential equation in $\mathrm{k}$ and therefore has a closed form solution conditional upon two boundary conditions. The solution in the family of solutions (4) that satisfies these boundary conditions is defined as $S(k(t))=x(t)$.

Consider two sets of boundary conditions corresponding to the two different regimes discussed above. The first regime is a switch from a floating exchange rate system to a fixed rate system. In this case, when the exchange rate hits a given value, $x^{a}$, it will remain fixed forever ("a" stands for "absorbing.") Therefore, at this point, the expected change in the exchange rate is zero so that by (1), $x^{\wedge}=k^{\wedge}$, where $k^{\star}$ is the fundamental level determining $x^{a}$; i.e., $x^{a}=S\left(k^{a}\right)$. The second regime is a band policy where exchange rates are reflected with infinitesimal interventions at boundaries $\underline{\mathrm{k}}, \overline{\mathrm{k}}$ where $\underline{\mathrm{k}}<$ $\bar{k}$. Therefore, at the boundaries, $G^{\prime}(\underline{k})=G^{\prime}(\bar{k})=0$. Froot and Obstfeld $(1991 \mathrm{a}, \mathrm{b})$ show how the solutions can be derived from these boundary conditions.

While assuming no official intervention except at the boundaries provides simple closed-form solutions, it suggests that governments take no action to offset private capital flows except at the boundaries. In some cases, this assumption may indicate misleading implications for the behavior of asset prices and their determinants. An example of these implications will be demonstrated below in the case of intervention around bands. Before examining this case, however, I first consider the case of a switch from a float to a fixed rate system examined by Flood and Garber (1983). 


\section{Intra-Regime Controls Before a Switch to Fixed Rates}

The outbreak of World War I disrupted the world currency system previously fixed to gold. After intermittent attempts to fix the pound, the British floated the pound in 1919. Following the war, Britain began adjusting financial markets in preparation for the return of the pound to a fixed rate system. In 1925, the pound was fixed at its pre-war parity of $\$ 4.80 /$ pound sterling. Other examples of switches in exchange rate regimes from floating rates to fixed rates include the Greenback dollar following the Civil War as well as some European currencies following the Napoleanic Wars.

Intra-regime policy as usually treated as laissez faire in the literature so that simple processes for money supply can be assumed for tractability. 8 / However, historical accounts suggest that before the fixings, the authorities employed capital controls. For example, prior to the return to gold, the British authorities placed restrictions on movements of gold and prevented private holdings of gold. A major concern of British officials appeared to be that the pound would become unstable. $\underline{9}$ In an attempt to counter this instability, controls upon movements and ownership of gold were intermittently placed and removed.

These accounts suggest several aspects of the official intervention within the pre-fix regime. First, capital controls were aimed at stabilizing currency movements. Second, the occasional nature of these restrictions indicates that traders in international capital markets perceived the likelihood of official intervention as uncertain. Third, these controls became more common as the pound approached its pre-war parity level and the British authorities became more committed to returning the pound to a gold standard. Fourth, during periods of controls and other official intervention, some amount of private excess demand for gold were unmet over some intervals of this period.

8/ See, for example, Flood and Garber (1983) and Froot and Obstfeld (1991a).

9/ See, for example, the discussion in Yeager (1976) and Moggridge (1972). 
I next show that by incorporating the authorities response to exogenous movements in money demand, I can obtain a stylized characterization of the movement in incipient excess demand in the foreign exchange market. Based upon this characterization, I then consider the effects in equilibrium arising from official intervention. For this purpose, I follow the standard assumption that private excess demand for foreign exchange follows Brownian motion as given in (3). Given this process, an intervention policy placing capital restrictions before the fix should contain the basic features described above: (a) the policy should offset incipient movements in private fundamentals to stabilize the exchange rate; (b) the intervention should appear uncertain to traders; (c) the likelihood of intervention should increase as the exchange rate approaches its fix.

To describe these restrictions, I discretize the state-space of fundamentals and write the fundamentals process in (3) as a binomial process. Thus, let $\mathrm{k}$ range over values such that:
(5) $\mathrm{k}_{\mathrm{i}+1}-\mathrm{k}_{\mathrm{i}}=\xi$
$\forall \mathrm{i}$,

where starting at $k_{i}$, a small period of time $\tau$ later the following would be observed:

$k_{i-1}$ with probability $p$

$k_{i+1}$ with probability $q$,

where $\mathrm{p}=(1 / 2)(1-(\mu \tau / \xi)) ; \mathrm{q}=(1 / 2)(1+(\mu \tau / \xi))$. Now suppose that the authorities intervene to stop movements in fundamentals with some probability. Define the fundamentals process distorted by fundamentals to be $f(t)$. Then, the probability of intraregime intervention can be written: 


$$
\pi(f), \text { for } f \in\left(\underline{f}, f^{\prime}\right), \pi^{\prime}(f)>0 \text {, }
$$

where $\mathrm{f}$ is the level of fundamentals at the fix rate, $x^{*}$, and $\underline{f}$ is a lower support of the probability distribution (which could be $-\infty$ ). Thus, as fundamentals reach an upper level, intervention occurs with certainty.

Since official interventions are directed toward offsetting capital movements, I assume for simplicity that when interventions occur, they completely offset the excess private demand for currency. Then, if at time $t, k_{i}=f_{i}, \tau$ periods later the following would be observed:

$\mathrm{f}_{\mathrm{i}-1}$ with probability $\mathrm{p}\left(1-\pi\left(\mathrm{f}_{\mathrm{i}}\right)\right)$

$f_{i+1}$ with probability $q\left(1-\pi\left(f_{i}\right)\right)$

$\mathrm{f}_{\mathrm{i}}$ with probability $\pi\left(\mathrm{f}_{\mathrm{j}}\right)$.

In other words, fundamentals are allowed to move with probability $1-\pi(f)$, but are restricted with probability $\pi(f)$. In the event that fundamentals reach the upper level, $\mathbf{f}$, fluctuations are offset with probability one. In this case, the fundamentals process is "absorbed" at the new fixed exchange rate level, $x^{2}$.

This discrete time process may be approximated as a continuous process by taking the limit as the interval of time, $\tau$, becomes small. For this purpose, I consider the changes in fundamentals over the interval of time $\tau$, and index this process as $f_{0_{0}}, f_{r}, f_{2 r}$, $\ldots, f_{n}$. I then define the family of sigma algebras generated by this sequence as $\Omega_{\mathrm{a}}$. And finally $I$ create the continuous time process as: $f_{t}=f_{a r}$. If it exists, the limit diffusion has the form: 10 /

10/ See for example Karlin and Taylor (1981). 
(7) $d f=a(f) d t+b(f)^{1 / 2} d z$

$$
\begin{gathered}
\text { where } a(f)=\lim _{\tau \rightarrow 0} \tau^{-1} E\left\{\left(f_{(\mathrm{n}+1) \tau}-{ }_{\tau} \mathrm{f}_{\mathrm{n} r}\right) \mid \Omega_{\tau} \Omega_{\mathrm{n} \tau}\right\} \\
\qquad \begin{aligned}
\mathrm{b}(\mathrm{f})= & \lim _{\tau \rightarrow 0} \tau^{-1} \mathrm{E}\left\{\left(\mathrm{f}_{(\mathrm{n}+1) \tau}-{ }_{\tau} \mathrm{f}_{\mathrm{ar}}\right)^{2} \mid{ }_{\tau} \Omega_{\mathrm{a} \tau}\right\} .
\end{aligned}
\end{gathered}
$$

The appendix shows that this limit diffusion is described in the following proposition.

Proposition 1: Within the boundaries, the limit diffusion of the fundamentals process (5) distorted by the intra-regime intervention policy (6) is:

$$
\mathrm{df}=\mu(1-\pi(\mathrm{f})) \mathrm{dt}+\sigma(1-\pi(\mathrm{f}))^{(1 / 2)} \mathrm{dz}
$$

The conditional mean of fundamentals is,

$$
E(\mathrm{df} \mid \mathrm{f})=\mu(1-\pi(\mathrm{f})),
$$

while the conditional variance is,

$$
\mathrm{E}\left((\mathrm{df})^{2} \mid \mathrm{f}\right)=\sigma^{2}(1-\pi(\mathrm{f})) .
$$

The intuition behind this result is straightforward. When no restrictions or intervention occur, fundamentals evolve according to (3) with constant conditional mean, $\mu$, and variance, $\sigma^{2}$. However, with the intervention policy (6), the authorities will intervene to offset capital movements with greater frequency. With probability $\pi(\mathrm{f})$, capital movements and, hence, the exchange rate are stabilized.and the conditional mean and variance are zero. However, with probability $(1-\pi(f))$, these variables are allowed to 
move. Since $\pi(f)$ approaches one at the boundary, it is clear that both the conditional mean and variance approach zero as the probability goes to one.

Since the distribution of $f$ has an absorbing barrier at $\mathrm{f}$, the asymptotic distribution of $f$ is a mass concentrated at the fixed rate fundamentals level, $\mathrm{f}$. To evaluate the behavior of fundamentals before reaching the fixed rate, however, I consider the distribution of $f$ if its upper boundary occured before the absorption point $\mathrm{f} .11 /$ The appendix shows that this distribution is given as described in the following proposition.

Proposition 2: The distribution of fundamentals given by (8) will asymptotically be concentrated at a mass point $f^{3}$. The distribution of fundamentals given by (8) with a (reflecting) boundary $\mathrm{f}^{\prime}<\mathrm{f}^{\mathrm{a}}$ and starting (non-absorbing) state $\underline{\mathrm{f}}$ is given by:

$$
\begin{aligned}
p(f)= & A \exp \left\{\left(2 \mu / \sigma^{2}\right) f\right\} /(1-\pi(f)) \quad \text { for } \mu \neq 0, \\
& =A /(1-\pi(f)) \quad \text { for } \mu=0,
\end{aligned}
$$

where $A=\left[\sigma^{2} \int_{!}^{f}\left(\exp \left\{\left(2 \mu / \sigma^{2}\right) x\right\} /(1-\pi(x)) d x\right]\right.$.

Figure 1 depicts this distribution for the case of a truncated standard normal distribution where the probability $\pi(f)$ is truncated at $0.65 .12 /$ This distribution is based upon two assumptions about the drift and variance parameters, $\mu / \sigma^{2}=0$ and 1 . As the figures show, the fundamentals are concentrated near the upper boundary. This increasing concentration occurs even though the absorbing barrier has not been reached because the

$11 /$ In other words, I assume that the boundary, $\mathrm{f}<\cdot \mathrm{f}$, is a reflecting barrier, but only for this comparison.

12/ Clearly, as the truncation values for $\pi(f)$ become nearer one, stabilization occurs more frequently and hence more of the mass becomes concentrated near the upper boundary. Results based upon a uniform distribution gave qualitatively similar results, affecting only the degree of curvature of the fundamentals distribution. 
fundamentals process becomes stabilized with greater frequency as fundamentals approach f.

For comparison, the figure also depicts the analogous distribution for fundamentals when they follow Brownian motion in the barid. As the figure demonstrates, when $\mu=0$ the fundamentals are uniformly distributed. When $\mu=1$, the process is concentrated near the band but with less density.

Having described the process in the presence of intra-regime intervention, the exchange rate can be solved in the Froot-Obstfeld framework given above. First, I assume that the family of solutions is given by a twice-differentiable function, $G(f)$. Then, I apply Ito's Lemma to this function using the process given in (8) to obtain $E\{d x(t) \mid W(t)\}$. Next, I substitute this expression into the exchange rate equation (1), implying:

$$
\mathrm{G}(\mathrm{f})=\mathrm{f}+\alpha \mu(1-\pi(\mathrm{f})) \mathrm{G}^{\prime}(\mathrm{f})+\alpha \sigma^{2}(1-\pi(\mathrm{f})) \mathrm{G}^{\prime \prime}(\mathrm{f})
$$

As before, this equation is a second-order difference equation in $\mathrm{f}$, although the coefficients on the first and second order terms are now functions of $f$ as well. For the case of a fixed exchange rate boundary, the unique solution to this differential equation will be the solution that imposes $x^{a}=f^{2}$. For given functional forms for the probability $\pi(f)$, this equation can be solved numerically.

Figure 2 describes the solution for the case where $\mu>0$ and where $\pi$ is a truncated normal distribution. For comparison, this solution is first compared with the solution in Froot and Obstfeld (1991a) assuming two absorbing barriers, $\underline{x}^{\mathbf{a}}\left(\underline{f}^{\mathrm{a}}\right)$ and $\overline{\mathrm{x}^{\mathrm{a}}}\left(\overline{\mathrm{f}}^{\mathrm{a}}\right)$. The probability of intervention increases from $\underline{\mathbf{P}}$ until reaching $\dot{\overline{\mathrm{f}}}$. As the figure shows, the stabilizing intervention tends to keep the exchange rate closer to the $45 \%$ line at every level 
of fundamentals.13/ The intuition for this result is straightforward. As fundamentals approach $x^{*}$, the probability that intervention will stop the movement in fundamentals increases. Thus, traders expect a lower conditional mean growth rate of fundamentals. They therefore bid up the value of domestic currency relative to the no intra-regime intervention case. As a result, the domestic currency is more valuable. On the other hand, as fundamentals approach the lower bound, the likelihood of intervention approaches zero. In this case, the exchange rate approaches the solution as in the case of the no intra-regime intervention case. More realistically, when $\underline{\mathbf{p}}=-\infty$ so that the fix only occurs at the point $\mathrm{f}^{\mathbf{a}}$, the solution is as described in the dashed line in the figure.

The probability density of exchange rates may be derived from this solution together with the fundamentals density in Proposition 2 since through the change-of-variable formula: $p(x)=p(f) / x^{\prime}(f)$. As is evident from Figures 1 and 2 , the exchange rate distribution would be concentrated near the fixed exchange rate point if $\mu>0$.

\section{Intra-Regime Intervention When Rates Are Targeted Within Bands14/}

Another regime that has important practical applications arises from a policy that targets rates within given bands. Regimes of this type include fixed rate systems when central banks allow exchange rates to fluctuate within given bands, managed float systems where the bands are not official such as G-3 intervention following the Louvre Accord, and policies aimed at targeting interest rates within fluctuating bands such as in the 1970s.

The solutions to asset prices when fundamentals follow Brownian motion everywhere except at the boundary regime points are given by the Froot-Obstfeld solution (4).

$\underline{13}$ If the probability increases from $\underline{\mathrm{f}}$ sufficiently quickly, it is possible to generate some perverse cases where the intra-regime intervention solution crosses the standard solution near $\mathrm{f}$. Even in this case, however, the intra-regime intervention solution approaches $\mathrm{x}^{4}$ from below the standard solution as the intuition in the text describes. This perverse case dissappears as the lower bound $\underline{f}$ goes to $-\infty$, however.

14/ This section draws on Lewis (1995). 
However, empirical evidence for many applications of target band policies suggests that asset prices are almost never allowed to float freely within the band. For example, within the European Monetary System, frequent interventions have attempted to keep exchange rates away from the boundaries.

Empirical evidence suggests at least two features of this intervention policy. First, most interventions are directed toward keeping the exchange rate from moving away from the targeted level. In other words, when the currency depreciated, the central bank bought domestic currency, and vice versa. Second, fewer interventions were directed toward stabilizing movements in the exchange rate. In this case, interventions tried to stop movements in the exchange rate regardless of its direction. 15 /

Using the same approach as above, I consider the stylized effects upon fundamentals when traders view the interventions by monetary authorities as uncertain. As above, I assume that the market-determined fundamentals process follows the Brownian motion in (3). Facing this process of fundamentals, the authorities primarily intervene to offset movements away from the target level, but also occasionally wish to stabilize the exchange rate at the current level. A representation of this policy is to specify: "when fundamentals move away from the target level, 'offet with probablity $\pi^{\prime \prime}$; when fundamentals move toward the target level, offset with probability $\pi^{\mathrm{d}}$, where $\pi^{\mathrm{u}}>\pi^{\mathrm{d}}$."

More formally, if I define the target level as $\mathbf{x}^{\mathrm{T}}\left(\mathrm{f}^{\mathrm{T}}\right)$, then a characterization of this rule is to assume that the probability of intervention increases with the deviation of $f$ from $f^{T}$. Furthermore, if I define the bands around the target rate as $\left(f_{r}, \bar{f}\right)$, this probability can be assumed to equal one at these bands. At these bands, the probability of a reflecting intervention equals one, bringing the fundamentals back inside the bands. Finally, the

15/ For evidence of this behavior within the French franc/Deutschemark rate, see Edison and Kaminsky (1990). 
probability function should ensure that the probability of movements away from the target level, $\mathrm{f}^{\mathrm{T}}$, is offset with greater frequency than movements toward the target level.

I incorporate these features into the following stylized intervention policy summarized by a probability function. In the case where the bands are symmetric, I define this probability of intervention as:

$$
\pi\left(\left|\mathrm{f}-\mathrm{f}^{\mathrm{T}}\right|\right) \text {, where } \pi^{\prime}>0, \mathrm{f} \in\left(\underline{\mathrm{f}}^{\mathrm{f}}, \overline{\mathrm{f}^{\mathrm{f}}}\right) \text {. }
$$

This function implies that the probability of intervention increases until it reaches the bands.

The essential features of the intervention policy described above can be captured with this specification. For example, suppose that $f>f^{T}$. Then I characterize the intervention process and its effect upon the market-determined fundamentals process by writing the process in terms of the discretized state-space representation given in (5). If at time $t, k_{i}=$ $\mathrm{f}_{\mathrm{i}}, \tau$ periods later the following would be observed:

(11) $\mathrm{f}_{\mathrm{i}-1}$ with probability $\mathrm{p}\left(1-\pi\left(\mathrm{f}_{\mathrm{i}-1}\right)\right)$

$f_{i+1}$ with probability $q\left(1-\pi\left(f_{i+1}\right)\right)$

$f_{i}$ with probability $\left.p \pi\left(f_{i-1}\right)+q \pi\left(f_{i+1}\right)\right)$.

Since $\pi$ is increasing in $f$, the probability of intervening in the case of a movement away from the target, $\pi\left(f_{i+1}\right)$, is less than the probability of intervention when moving towards the target, $\pi\left(\mathrm{f}_{\mathrm{i}-1}\right)$. Thus, the probability of intervention in the case of movements away from the band are $\pi^{\prime \prime}=\pi\left(f_{i+1}\right)$, while the probability of intervention in case of movements toward the band are $\pi^{\mathrm{d}}=\pi\left(f_{\mathrm{i}-1}\right)$. Clearly, then $\pi^{\mathrm{d}}<\pi^{\mathrm{u}}$.

Though subtle, this distinction of the targeting probability from the absorbing barrier probability case yields important differences between the distributions of exchange rates. Since interventions to counteract movements away from the target occur more frequently than interventions to counteract movements toward the target, the intra-regime intervention 
induces mean-reverting behavior upon the asset price. This mean-reverting behavior was absent from the intervention policy in (6) aimed at stabilizing the exchange rate alone.

To formalize the process, I make the probability function a continuous function of $f$ for all $f \in(\underline{f}, \bar{r})$. A differentiable transformation of the arguments of $\left|f-f^{T}\right|$ is useful for this purpose. Define this transformation as, $b\left(f ; f^{1}\right)$, where $b$ is everywhere continuous and differentiable, $b$ is a monotonic transformation of $\left|f-f^{\top}\right|$, and $\operatorname{sign}\left(f-f^{\top}\right)=$ $\operatorname{sign}(\mathrm{db} / \mathrm{df}) .16 /$ In this case, the probability may be rewritten as $\pi\left(b\left(f ; f^{7}\right)\right)$. For simplicity, I subsume the target fundamental arguement $\mathrm{f}^{\mathrm{T}}$ in the discussion below and simply write $\pi(\mathrm{f})=\pi\left(\mathrm{b}\left(\mathrm{f} ; \mathrm{f}^{\mathrm{T}}\right)\right) \cdot \underline{17}$

To see this more clearly, I approximate this discrete process with a continuous time limit process. For this purpose, I consider the changes in fundamentals over the interval of time $\tau$, indexed as before: $f_{0,}, f_{\tau}, f_{2 \tau}, \ldots, f_{n r}$. I then create the continuous time process as: $f_{t}={ }_{t} f_{n}$. If it exists, the limit diffusion has the form given in (7). The appendix shows that this limit diffusion is described in the following proposition.

Proposition 3: Assuming $\pi(f)$ is continuous and differentiable everywhere on $\left(\underline{f}^{\top}, f^{f}\right)$ with $(\mathrm{d} \pi / \mathrm{df}) \neq 0$ at boundaries, the limit diffusion of the fundamentals process (3) distorted by the intra-regime intervention policy (11) is:

$$
\mathrm{df}=\left\{\mu(1-\pi(\mathrm{f}))-\sigma^{2}(\mathrm{~d} \pi / \mathrm{df})\right\} \mathrm{dt}+\sigma(1-\pi(\mathrm{f}))^{(1 / 2)} \mathrm{dz}
$$

The conditional mean of fundamentals is,

$$
E(d f \mid f)=\mu(1-\pi(f))-\sigma^{2}(d \pi / d f),
$$

16/ An example of such a transformation is $b=\left(f-f^{\top}\right)^{2}$ which is clearly differentiable everywhere and has a derivative that preserves the sign of the argument, $f-f^{\mathrm{T}}$.

17. Clearly, $\mathrm{d} \pi / \mathrm{df}=(\mathrm{d} \pi / \mathrm{db})(\mathrm{db} / \mathrm{df})$ where $\mathrm{d} \pi / \mathrm{df}>0$ for $\mathrm{f}>\mathrm{f}^{\mathrm{T}}$, and $\mathrm{d} \pi / \mathrm{df}<0$ for $\mathrm{f}$ $<\mathrm{f}^{\mathrm{T}}$. 
while the conditional variance is,

$$
\mathrm{E}\left((\mathrm{df})^{2} \mid \mathrm{f}\right)=\sigma^{2}(1-\pi(\mathrm{f})) .
$$

This process has a straightforward and intuitive interpretation. The first term in the conditional mean depends upon the drift in the private market fundamentals. As for the stabilizing intervention described for the return to a fix, the expected drift equals the drift in the absence of intervention, $\mu$, multiplied by the probability of no intervention, $1-\pi(f)$. This component of the conditional mean is the same as that of the stabilizing intervention policy described in Proposition 1. However, intervention policy within the band also contains an additional term given by $\sigma^{2}(\mathrm{~d} \pi / \mathrm{df})$. This term reflects the fact that interventions to keep the exchange rate from moving away from the target level are offset with greater frequency than interventions when the exchange rate moves towards the target. The local difference between these two probabilities is the gradient at $f,(d \pi / d f)$. The expected effect upon the fundamentals depends upon the variability of fundamentals $\sigma^{2}$ within the time interval, $\tau$. Since $(d \pi / d f)$ is positive when $f>f^{\mathrm{f}}$ and negative when $f<$ $\mathrm{f}^{\mathrm{T}}$, this policy induces a mean-reverting effect upon the fundamentals process.

This mean-reversion generates a clustering of fundamentals within the band as the following proposition shows.

Proposition 4: The asymptotic distribution of fundamentals given by (12) is:

$$
\begin{aligned}
\mathrm{p}(\mathrm{f}) & =\mathrm{A} \exp \left\{\left(2 \mu / \sigma^{2}\right) \mathrm{f}\right\}(1-\pi(\mathrm{f})) \quad \text { for } \mu \neq 0 \\
& =\mathrm{A}(1-\pi(\mathrm{f})) \quad \text { for } \mu=0
\end{aligned}
$$

where $A=\left[\sigma^{2} \int_{\underline{f}}^{7}\left(\exp \left\{\left(2 \mu / \sigma^{2}\right) x\right\}(1-\pi(x)) d x\right]\right.$. 
Figure 3 depicts this distribution in the upper panel when the probability is uniformly distributed on $\underline{\mathrm{f}}^{\mathrm{r}}, \overrightarrow{\mathrm{f}}^{\mathrm{f}}$, and where $\mathrm{b}=\left(\mathrm{f}-\mathrm{f}^{\mathrm{T}}\right)^{2}$. As another example, the second panel shows the distribution when the probability is logistically distributed with $\mathrm{b}=\left|\mathrm{f}-\mathrm{f}^{\mathrm{T}}\right| . \underline{18} \mid$ The lower panel depicts the probability for the standard case where fundamentals follow Brownian motion within the band. As the figure shows, the fundamentals process contains a mode at the midpoint of the band when $\mu=0$. When $\mu \neq 0$, the distribution is asymmetric in both cases.

I can now solve the exchange rate using the steps as above. Assuming a family of solution functions, $G(k)$, as before, I apply Ito's Lemma to this function using the process in (12) to obtain the expected change in the exchange rate. Substituting this expression into the exchange rate equation (1) yields:

$$
\mathrm{G}(\mathrm{f})=\mathrm{f}+\alpha\left[\mu(1-\pi(\mathrm{f}))-\sigma^{2}(\mathrm{~d} \pi / \mathrm{df})\right] \mathrm{G}^{\prime}(\mathrm{f})+\alpha \sigma^{2}(1-\pi(\mathrm{f})) \mathrm{G}^{\prime \prime}(\mathrm{f})
$$

As for the other families of solutions, equation (14) is a second-order differential equation that can be solved given a probability function, $\pi(f)$, and two boundary conditions. If the target zone regimes are fully credible, then traders will expect the exchange rate change at the bands to be zero. Thus, boundary conditions are provided by the condition that $G^{\prime}\left(\underline{f}^{\prime}\right)=G^{\prime}\left(\bar{f}^{\prime}\right)=0$.

Figure 4 depicts the exchange rate solution with and without intra-regime intervention for the case of $\mu=0$. Since intra-regime interventions offset movements in fundamentals away from the band, the future path of fundamentals is expected to be concentrated near the target fundamentals level. Therefore, the exchange rate is on-average closer to the

18/ Although this probability is not differentiable at $\mathrm{f}^{\mathrm{T}}$, this example was constructed to allow an instructive comparison across probability functions. 
target level for every given level of fundamentals with intra-regime intervention than in the standard case. $19 /$

As before, I combine the information from the distribution of fundamentals in Figure 3 and the exchange rate solution in Figure 4 to derive the exchange rate distribution from: $p(x)=p(f) / x^{\prime}(f)$. The implications for the empirical distribution of the exchange rate can be quite different from the standard model. In the standard model, the distribution is Ushaped with the mass of the distribution concentrated at the bands. With intra-regime intervention, however, a mode is concentrated at the center of the band, although exchange rate observations are also clustered near the bands in the asymptotic distribution.

Figure 5 depicts this distribution for the exchange rate with interventions within the band. Although the exchange rate distributions have very fat tails, the distribution is concentrated in the center of the band. Intuitively, intervention in fundamentals concentrates exchange rates near the center of the band and tends to keep exchange rates from nearing the band. In the infrequent events when the exchange rates near the bands, they are prevented from leaving the band so that they cluster at the boundaries. This clustering near the boundaries is the usual reason for the U-shaped distribution of exchange rates. In the case of intra-regime interventions, exchange rate observations in this part of the distribution can be less likely than at the midpoint.

To assess how likely exchange rates are to stray to the boundaries in the presence of intra-band intervention, Lewis (1991) conducts Monte Carlo experiments of the behavior of fundamentals and exchange rates under various assumptions about the probability of intervention. These experiments show that intra-regime intervention tends to keep the

19/ As in the switch to a fixed rate case, it is possible to generate perverse cases when the probability changes sufficiently quickly at the target level. In this case, the intraregime intervention solution above $\mathrm{f}^{\mathrm{T}}$ may cross and lie above the standard solution near $\mathrm{x}^{\mathrm{T}}$. However, the intra-regime solution later crosses and approaches the boundary point, $\mathrm{f}^{\mathrm{r}}$, from below. 
exchange rate away from the bands even in large samples. For example, a reasonable approximation of the observed component of the exchange rate distribution in large (but not infinite) samples, is the range depicted in Figure 5 as $\underline{\underline{x}}^{\mathrm{mc}}$ and $\overline{\mathbf{x}}^{\mathrm{mc}}$. Therefore, in reasonably sized samples with intra-band intervention, exchange rates may not be observed at the boundaries at all. This implication is consistent with empirical observations of exchange rates within the European Monetary System as well as other band regimes. $\underline{20 /}$

\section{Empirical Application of Intra-Regime Intervention}

In the analysis above, I demonstrated that some discrete time intervention policies that characterize actual policy aimed at stabilizing rates have continuous time approximations. These approximations allow for easy calculation of exchange rates conditioned upon expected future policies both within the regime and at the boundaries.

In addition to the easy comparisons between intra-regime intervention and existing results assuming Brownian motion, these processes allow for straightforward comparison with actual intervention data that is frequently dichotomous.

a. Returning to a Fix The solution when the authorities will fix the exchange rate in the future was described in Figure 2 and equation (10). However, the effects of intervention upon actual capital flows are often difficult to detect since these flows are restricted. For example, prior to the return to the gold, the British authorities intermittently placed various restrictions upon gold movements because they were concerned about destabilizing influences from arbitrage between New York and London.21/

Assuming that these restrictions were temporarily stabilizing, however, one can approximate the effects upon fundamentals by treating these intervention policies according

20/ For a description of this empirical evidence, see Flood, Rose, and Mathieson (1991).

21/ For example, see the discussion in Moggridge (1972). 
to the intervention rule in (6). In this case, the empirically implied exchange rate solution for (10) can be obtained in the following way. First, collect data on months (or weeks) when restrictions were placed on capital flows. Second, based upon these data, estimate a probability of intervention function, $\pi(\mathrm{f})$, using data on fundamentals. Alternatively, if there is no reliable candidate measure of fundamentals, the equilibrium relationship between $x(f)$ and $f$ can be used to estimate $\pi(f)=\pi\left(G^{-1}(x)\right)$. Next, using the empirical estimate of $\pi$, together with given values of the exogenous parameters, $\alpha, \mu$, and $\sigma$, calculate the solution given in equation (10). Solving this function requires specifying a boundary condition, $\mathrm{x}^{\mathrm{a}}$. This boundary likely will be available from ex post knowledge of the fix, but may also be the point where $\pi=1$.

Since these solutions depend upon the exogenous parameters, sensitivity analysis may also be used to examine how these solutions vary with the parameters. These solutions may likewise be compared to actual data on exchange rates.

b. Target Zones An alternative and timely application is the analysis of interventions within the bands of an official targetted band. For example, much of the intervention within the European Monetary System occurs inside the official target bands. In this case, it is also natural to consider intervention as an unobserved variable, since these magnitudes are generally not known to traders in the market.

One can evaluate the exchange rate solution, however, assuming that these restrictions were temporarily stabilizing, and generally kept exchange rates from moving too far from their target levels. Thus, the effects upon fundamentals may be approximated by treating these intervention policies according to the intervention rule in (11). In this case, the empirically implied exchange rate solution for (14) can be obtained following similar steps as above. First, collect data for days when central banks are observed intervening, including possibly whether interventions are domestic currency sales or purchases. Second, based upon these data, estimate a probability of intervention function using either 
fundamentals or exchange rates as explanatory variables. Third, using the empirical estimate of $\pi 0$, together with given values of the exogenous parameters, $\alpha, \mu$, and $\sigma$, calculate the solution given in equation (14). In this case, solving this function requires specifying the target bands, $\underline{x}^{r}, \overline{x^{r}}$. In cases where the bands are official and known, these bands will be known. However, in cases where bands are not known, the probability functions can help tie down these boundaries. Lewis (1995) provides an example of this latter case for the Group of 3 during the period following the Louvre Accord. As for the fixed rate case, the empirical fit of this solution may evaluated by conducting sensitivity analysis with respect to the exogenous parameters.

\section{Extensions of Intra-Regime Intervention Policies}

The intra-regime intervention policies have been discussed above in the case of two regimes where the boundary conditions are known and constant over time. However, other regimes have been considered in recent literature on target zones. For example, Bertola and Caballero (1992) assume that when the fundamentals process reaches the upper boundary, $x^{a}$, the authorities devalue with probability $h$ to push the exchange rate into the middle of the next band. Alternatively, with probability $(1-h)$, they push the exchange rate back inside the band to the central parity level. Similarly, when the process reaches the lower boundary, $x^{a}$, the authorities revalue with the same probability or else push the exchange rate back to the central parity level inside the band.

The solution described in (14) can easily be used to generate a similar regime. A given pair of the probability of realignment at the bands, h, and a size of realignment, c, provide two boundary conditions with which to calculate the unique solution to (14). As Figure 1 shows, this solution concentrates the fundamentals process, and hence the exchange rate near the center of the band. Therefore, it is not necessary to assume that the magnitude of the jump must be large, as Bertola and Caballero (1992) do. 
Another set of solutions is considered by Bertola and Svensson (1993). They incorporate the realignment state into the exchange rate solution as an additional state variable. The intra-regime fundamentals process in Proposition 3 could be incorporated into a solution of this type to allow for intervention within the bands as well as at the bands.

\section{Concluding Remarks}

In this paper, I have described a class of discrete time processes that may be viewed as the market-determined fundamentals process after being distorted by stabilizing intervention policies. These processes are shown to have simple single-state continuous time approximations that allow for easy solutions in the framework described by Froot and Obstfeld (1991a). An important feature of these processes are that they generate plausible distributions for the behavior of the fundamentals and, thereby, the exchange rate. These distributional implications are closer to the evidence found in real world applications.

Also, in contrast to other mean-reverting processes for fundamentals, these processes can be easily combined with empirical observations of official interventions. The magnitudes of these interventions are typically unobserved by market participants and could be considered latent variables. Thus, the likelihood of intervention can be estimated and incorporated into the analytical solution of the exchange rate in a natural way. As such, this approach can be used to empirically evaluate the implications of the exchange rate solutions provided by the model.

While I have focused upon examples from "credible" regimes with constant boundaries, the processes can easily be incorporated into alternative regimes including probabilities of realignments. Also, the processes can be incorporated into exchange rate solutions involving more than one state variable. Thus, these processes should prove useful for both theoretical and empirical applications of stochastic regime switching. 


\section{APPENDIX}

Proof of Proposition 1: As described in the text, the limit diffusion will have the form (7) if it exists. Use the process of fundamentals evaluated at intervals $\tau, f_{r}, \ldots, f_{\mathrm{n} r}$, and the continuous time process: $f_{t}={ }_{\tau} f_{a r}$. Also, define the standard Weiner process observed over these intervals as, ${ }_{\tau} z_{(\mathrm{n}-1) \tau},{ }_{7}, \ldots$, the process can be written: $\underline{22}$

$$
\text { (A1) } \begin{aligned}
f_{(\mathrm{a}+1) \tau} & =f_{f_{n}}+\sigma_{\tau} z_{(\mathrm{n}+1) \tau}+\mu \tau, \quad \text { when no intervention } \\
& =f_{\mathrm{n} r}, \quad \text { when intervention. }
\end{aligned}
$$

The conditional mean is:

$$
\mathrm{E}\left[\tau^{-1}\left(\mathrm{f}_{(\mathrm{n}+1) \tau}-\mathrm{f}_{\mathrm{n} \tau}\right) \mid \Omega_{\tau} \Omega_{\mathrm{n} \tau}\right]
$$

where $\tau_{\tau} \Omega_{\mathrm{a} r}$ is the sigma algebra generated by ${ }_{\tau} \mathrm{f}_{\mathrm{ir}}, \forall \mathrm{i}$. From the market driven process of fundamentals (5), together with intervention as in (A1), this process is clearly Markovian. Therefore, the conditional mean is

$$
\mathrm{E}\left\{\tau^{-1}\left(\sigma_{\tau} \mathrm{z}_{(\mathrm{n}+1) \tau}+\mu \tau\right)\left[1-\pi\left({ }_{\tau} \mathrm{n}_{\mathrm{n} \tau}\right) \mid{ }_{\tau} \Omega_{\mathrm{a} \tau}\right] .\right.
$$

Or, taking limits,
(A2) $\lim E\left[\tau^{-1}\left(f_{(\mathrm{n}+1) \tau}-f_{\mathrm{a} \tau}\right): \Omega_{\tau} \Omega_{\mathrm{n} \tau}\right]=\mu\left(1-\pi\left(f_{\mathrm{f}}\right)\right)=\mu(1-\pi(\mathrm{f}))$.
$\tau \rightarrow 0$

Similarly, the conditional variance is given by:

(A3) $\lim \mathrm{E}\left[\tau^{-1}\left(\mathrm{f}_{\mathrm{k} \tau}-{ }_{\tau} \mathrm{f}_{(\mathrm{k}-1) \tau}\right)^{2} \mid \Omega_{\mathrm{k} \tau}\right]=(1-\pi(\mathrm{f})) \sigma^{2}$.

$$
\tau \rightarrow 0
$$

22/ For example, see Nelson (1990). 
Next, defining $b(f)=\mu(1-\pi(f))$, and $a(f)=(1-\pi(f)) \sigma^{2}$, it is straightforward to show that the regularity conditions for non-explosion given in Stroock and Varadhan (1979) hold. Intuitively, the transformation $(1-\pi(f))$ bounds the conditional variance between zero and $\sigma^{2}$. Note that since this process is a continuous approximation of a discrete process that jumps discontinuously upon intervention, its diffusion limit only describes the expected evolution conditional upon any $\mathrm{f}$, and not the actual evolution.

Proof of Proposition 3: Write the process as in (A1). This implies that the conditional mean and variance can be written as in (A2) and (A3) respectively. In the present case, the probability of intervention depends upon the expected evolution of market fundaemntals as described in (11). Therefore, the expected evolution of the probability of intervention during $\tau$ can be written as a function of the expected evolution of market fundamentals:

$$
\begin{aligned}
& \pi\left(\mathrm{k}_{(\mathrm{n}+1) \tau}\right)=\pi\left({ }_{\tau} \mathrm{k}_{\mathrm{n} \tau}\right) \\
& +\pi,\left(\mathrm{k}_{\mathrm{n} \tau}\right)\left({ }_{\tau} \mathrm{k}_{(\mathrm{n}+1) \tau}-\tau \mathrm{k}_{\mathrm{n} \tau}\right)+o(\tau),
\end{aligned}
$$

where $o(\tau)$ collects all terms that approach zero faster than $\tau$. Then, substituting (A4) and (A1) into (A2) and using the fact that, conditional upon no interventions, $\left(k_{(n+1) \tau}-, k_{n \tau}\right)=$ $\left(f_{(n+1) \tau}-f_{n r}\right)$, the conditional mean can be written:

$$
\begin{aligned}
& \mathrm{E}\left\{\tau ^ { - 1 } ( \sigma , X _ { ( \mathrm { n } + 1 ) \tau } + \mu \tau ) \left[1-\pi\left(\mathrm{k}_{\mathrm{n} \tau}\right)\right.\right. \\
& \left.\left.\quad-\pi^{\prime}\left(\mathrm{k}_{\mathrm{n} \tau}\right)\left(\sigma, X_{(\mathrm{n}+1) \tau}+\mu \tau\right)+o(\tau)\right]\left.\right|_{\tau} \Omega_{\mathrm{n} \tau}\right\} .
\end{aligned}
$$

For starting fundamentals level, $f_{n \tau}={ }_{n} k_{\mathrm{a} \tau}$, taking the limit as $\tau$ goes to zero gives, 
(A6) $\lim E\left[\left.\tau^{-1}\left(f_{(\mathrm{n}+1) \tau^{-}}, f_{\mathrm{n}_{\tau} \tau}\right)\right|_{\tau} \Omega_{\mathrm{n} \tau}\right]=\mu\left(1-\pi\left(\mathrm{f}_{\mathcal{L}}\right)\right)-\pi^{\prime}\left(\mathrm{f}_{\mathcal{L}}\right) \sigma^{2}$. $\tau \rightarrow 0$

Similarly, substituting (A4) and (A1) into (A3), the conditional variance can be written:

(A7) $\lim E\left[\tau^{-1}\left(f_{(\mathrm{n}+1) \tau}-f_{\mathrm{n} \tau}\right)^{2} \mid{ }_{\tau} \Omega_{\mathrm{n} \tau}\right]=(1-\pi(\mathrm{f})) \sigma^{2}$. $\tau \rightarrow 0$

Therefore, define $\mathrm{b}(\mathrm{f}) \equiv \mu(1-\pi(\mathrm{f}))-\pi^{\prime}(\mathrm{f}) \sigma^{2}$, and $\mathrm{a}(\mathrm{f}) \equiv(1-\pi(\mathrm{f})) \sigma^{2}$ and substitute the result into (7) to yield to limit diffusion. To ensure that the non-explosive conditions hold, we require that $\pi(f)$ be continuous and differentiable with bounded first derivatives $\forall \mathrm{f} \in$ $\left(\underline{f}^{\mathrm{f}}, \overline{\mathrm{f}}\right)$. Furthermore, to guarantee that the fundamentals do not become absorbed at the boundaries, the strict inequalities $\pi^{\prime}\left(f^{\prime}\right)<0$ and $\pi^{\prime}\left(f^{\prime}\right)>0$ must hold.

Proof of Proposition 2: From Proposition 1, define the diffusion process in equation (8) as: $d f=a(f) d t+[b(f)]^{1 / 2} d z$ where $a(f) \equiv \mu(1-\pi(f)), b(f) \equiv \sigma^{2}(1-\pi(f))$. Then the Fokker-Planck forward equation provides the transitional density for $f \in(f, f)$,

(A8) $(\partial \mathrm{p} / \partial \mathrm{t})=\left(\partial^{2}[\mathrm{~b}(\mathrm{f}) \mathrm{f}] / \partial \mathrm{f}^{2}\right)-(\partial[\mathrm{a}(\mathrm{f}) \mathrm{p}(\mathrm{f})] / \partial \mathrm{f})$.

For a stationary density, $(\partial \mathrm{p} / \partial \mathrm{t})=0$. Therefore, setting the left-hand side of $(\mathrm{A} 8)$ equal to zero and twice integrating implies: $\underline{23 /}$

(A9) $p(f)=m(f)\left[C_{1} M(f)+C_{2}\right]$,

23/ For example, see Karlin and Taylor (1981), pages 219 - 221, or Wong (1964). 
where $m(f)=b(f) \exp \left[-\int_{\underline{f}}^{f}(2 a(\zeta) / b(\zeta)) d \zeta\right]$,

$$
M(f)=\int ! \exp \left[-\int_{\underline{f}}^{w}(2 a(\zeta) / b(\zeta)) d \zeta\right] d w,
$$

and where $C_{1}$ and $C_{2}$ are constants of integration that guarantee the following conditions:

(i) $\mathrm{p}(\mathrm{f}) \geq 0, \forall \mathrm{f} \in(\mathrm{f}, \mathrm{f})$,

(ii) $\int_{\underline{f}}^{f} p(\zeta) d \zeta=1$.

Substituting for $a(f)$ and $b(f)$ yields:

(A10) $\mathrm{p}(\mathrm{f})=\left[\sigma^{2}(1-\pi(\mathrm{f}))\right]^{-1} \exp \left\{\left(2 \mu / \sigma^{2}\right) \mathrm{f}\right\}\left[\mathrm{C}_{2}+\mathrm{C}_{1} \int_{!}^{\mathfrak{f}} \exp \left[-\left(2 \mu / \sigma^{2}\right) \zeta\right] \mathrm{d} \zeta\right]$

Condition (i) implies $\mathrm{C}_{1}=0$. Condition (ii) implies that:

$$
\left.C_{2}=\int_{\underline{f}}^{f}\left(\exp \left\{\left(2 \mu / \sigma^{2}\right) \zeta\right\} /(1-\pi(\zeta)) d\right\}\right] .
$$

Proof of Proposition 4: From Proposition 2, define the diffusion process in equation (12) as: $d f=a(f) d t+[b(f)]^{1 / 2} d z$ where $a(f) \equiv \mu(1-\pi(f))-\sigma^{2}(d \pi / d f)$, and $b(f) \equiv \sigma^{2}(1-\pi(f))$. Then following the same steps as in Proposition 2 through (A9) and substituting for $a(f)$ and $b(f)$,

(A11) $\mathrm{p}(\mathrm{f})=\left[\sigma^{2}(1-\pi(\mathrm{f}))\right] \exp \left\{\left(2 \mu / \sigma^{2}\right) \mathrm{f}\right\}\left[\mathrm{C}_{2}+\mathrm{C}_{1} \int_{!}^{\mathfrak{f}} \exp \left[-\left(2 \mu / \sigma^{2}\right) \zeta\right](1-\pi(\zeta)) \mathrm{d} \zeta\right]$.

Again, Condition (i) implies $\mathrm{C}_{1}=0$. Condition (ii) implies that:

$$
C_{2}=\int_{\underline{f}}^{\dot{f}}\left(\exp \left\{\left(2 \mu / \sigma^{2}\right) \zeta\right\}(1-\pi(\zeta)) d \zeta\right]
$$




\section{References}

Bertola, Giuseppe, and Ricardo J. Caballero, "Target Zones and Realignments," American Economic Review, No.3, 1992, 82, 520-536.

Bertola, Giuseppe, and Svensson, Lars, "Stochastic Devaluation Risk and the Empirical Fit of Target-Zone Models, " Review of Economic Studies, 1993, 60, 689-712.

Cook, Timothy, and Hahn, Thomas, "The Effect of Changes in the Federal Funds Rate Target on Market Interest Rates in the 1970s," Journal of Monetary Economics, November 1989, 24, 331-352.

Delgado, Francisco, and Dumas, Bernard, "Target Zones Broad and Narrow," in Paul Krugman and Marcus Miller, eds., Exchange Rate Targets and Currency Bands, Cambridge: Cambridge University Press, 1992, 35-58.

Edison, Hali, and Kaminsky, Graciela, "Target Zones, Foreign Exchange Intervention, and Exchange Rate Volatility," Working Paper, Federal Reserve Board of Governors, Washington D.C., December 1990.

Flood, Robert P., and Garber, Peter, "The Linkage Between Speculative Attack and Target Zone Models of Exchange Rates," National Bureau of Economic Research Working Paper, No. 2918, April 1989.

Flood, Robert P., and Garber, Peter, "A Model of Stochastic Process Switching," Econometrica, 1983, 51, 537-551.

Flood, Robert P., Rose, Andrew K., and Mathieson, Donald J., "An Empirical Exploration of Exchange Rate Target-Zones," Carnegie-Rochester Conference Series on Public Policy, Fall 1991, 35, 7-65.

Froot, Kenneth A., and Obstfeld, Maurice, "Stochastic Process Switching: Some Simple Solutions," Econometrica, January 1991a, 59, 241-250. (Check page number). 
Froot, Kenneth A., and Obstfeld, Maurice, "Exchange Rate Dynamics under Stochastic Regime Shifts: A Unified Approach," Journal of International Economics, 1991b, 31, 203-230.

Karatzas, Ioannis, and Shreve, Steven E., Brownian Motion and Shochastic Calculus. New York: Springer-Verlag, 1988.

Karlin, S., and H.M. Taylor, A Second Course in Stochastic Processes, (New York: Academic Press), 1981.

Krugman, Paul, "Target Zones and Exchange Rate Dynamics," Quarterly Review of Economics, August 1991, 106, 669-682.

Lewis, Karen K., "Occasional Interventions to Target Rates," University of Pennsylvania Working Paper, September 1991.

Lewis, Karen K., "Occasional Interventions to Target Rates," American Economic Review, September 1995, 85, 691-715.

Moggridge, D.E., British Monetary Policy 1924-1931, (Cambridge University Press: London), 1972.

Mussa, Michael L., "A Model of Exchange Rate Dynamics," Journal of Political Economy, February 1982, 90, 74-104.

Nelson, Daniel B., "Arch Models as Diffusion Approximations, " Journal of Econometrics, 1990, 45, 7-38.

Smith, Gregor, "Solution to a Problem of Stochastic Process Switching," Econometrica, January 1991, 59, 237-239.

Stroock, Daniel W., and S.R. Srinivasa Varadhan, Multidimensional Diffusion Processes, (Springer-Verlag: New York), 1979.

Svensson, Lars E.O., "Target Zones and Interest Rate Variability," Journal of International Economics, 1991, 31, 27-54. 
Wong, Eugene, "The Construction of a Class of Stationary Markoff Processes," Proceedings of Symposia in Applied Mathematics, Volume XVI, (American Mathematical Society: Providence, Rhode Island), 1964.

Yeager, Leland B., International Monetary Relations: Theory, History, and Policy, (Harper \& Row: New York), 2nd Ed., 1976. 


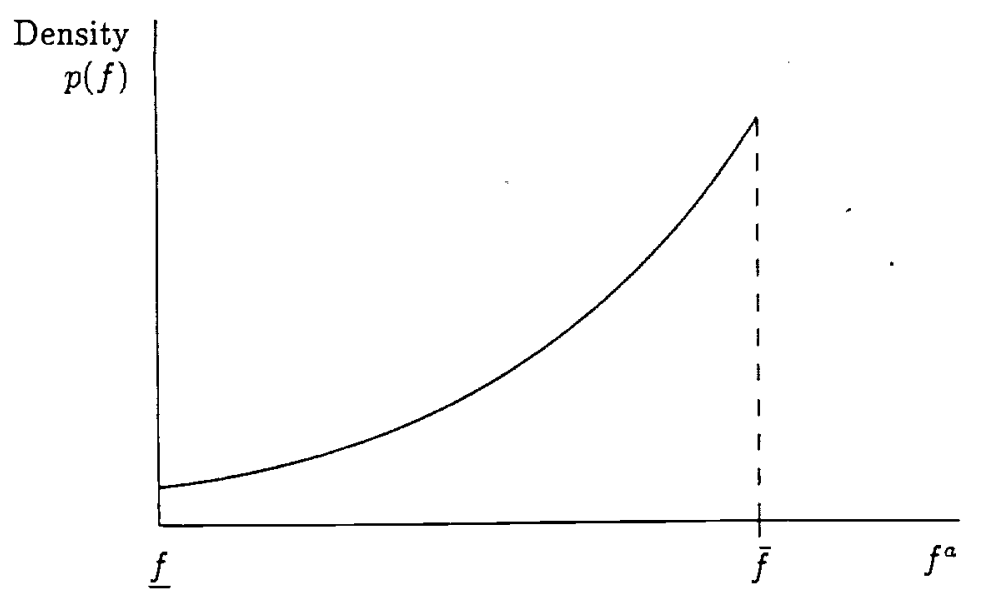

Intra-Regime

Stabilization

$$
(\mu=0)
$$

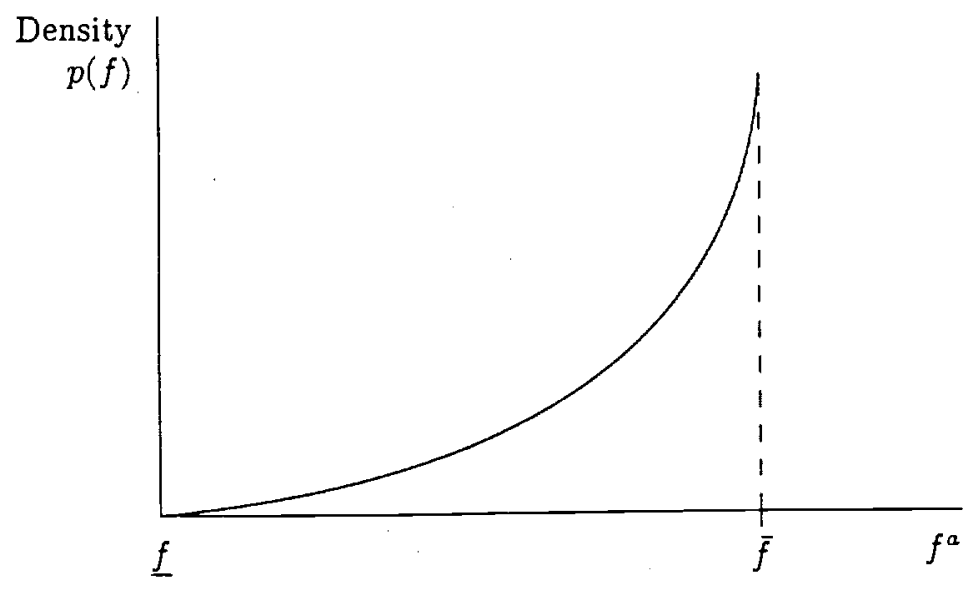

Intra-Regime Stabilization

$$
\left(\left(\frac{\mu}{\sigma}\right)=1\right)
$$

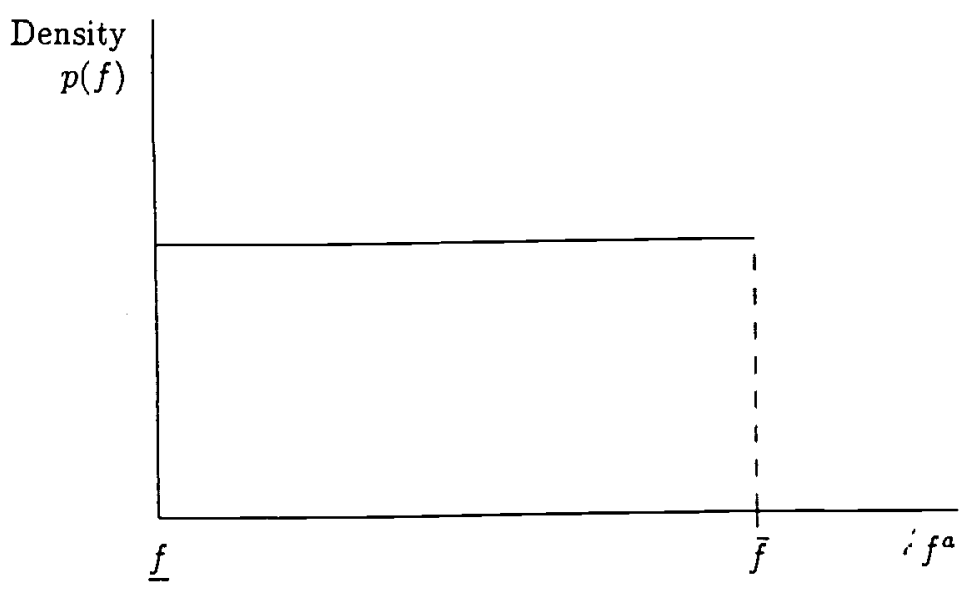

No Intra-Regime Stabilization

Figure 1: Fundamentals Distribution before Reaching a Fixed Rate Regime 


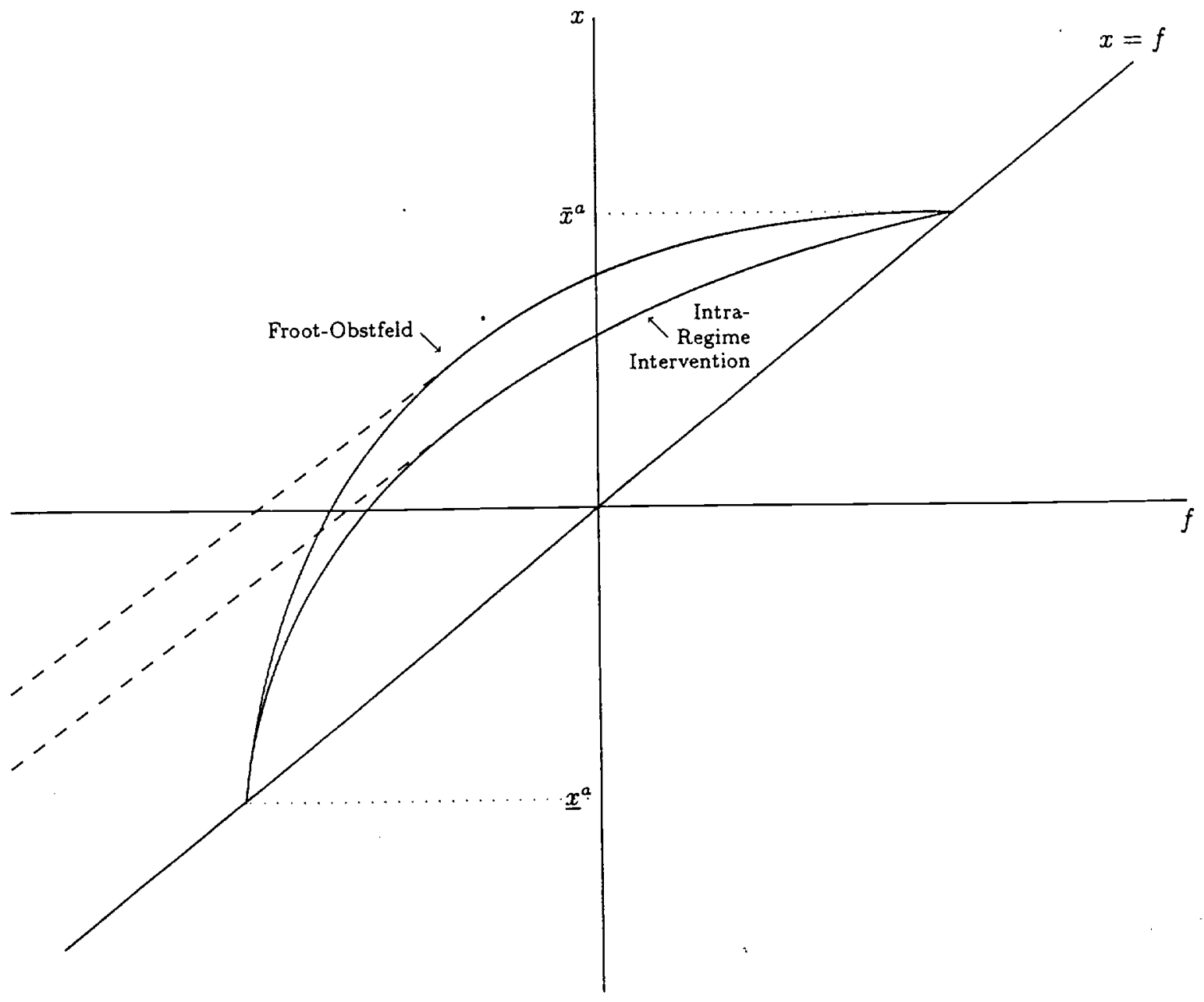

FIgURE 2: Exchange Rate Solutions for Switch to Fixed Rates 


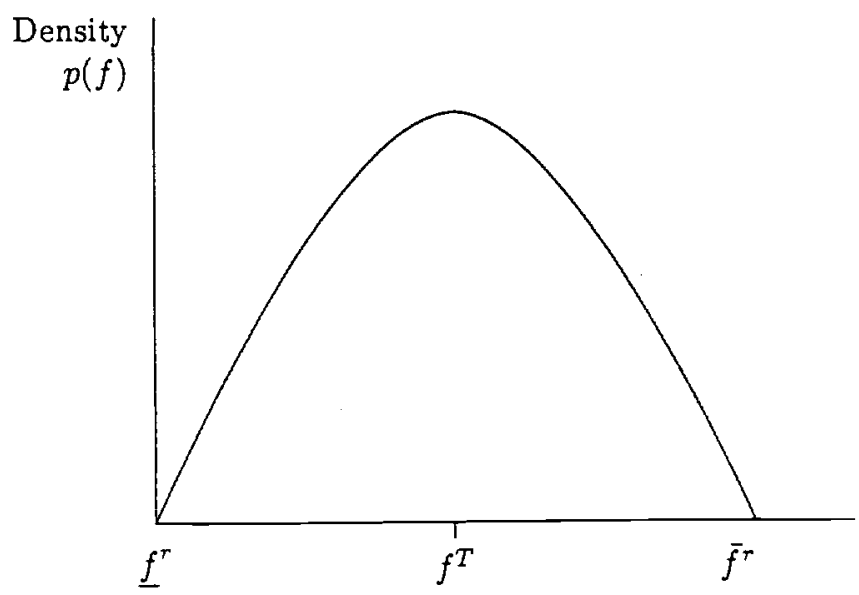

With

Intra-Band

Intervention

Probability

Uniform

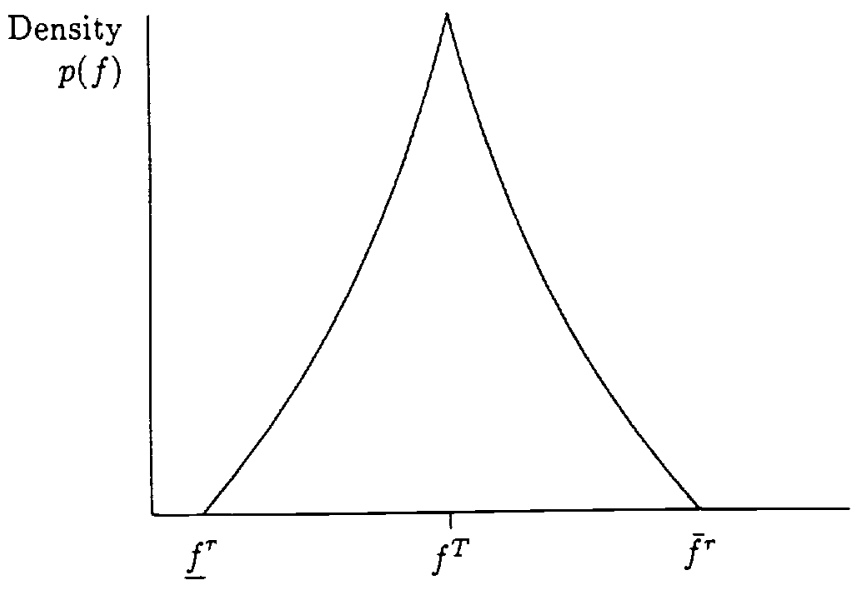

With

Intra-Band

Intervention

Probability

Logistic

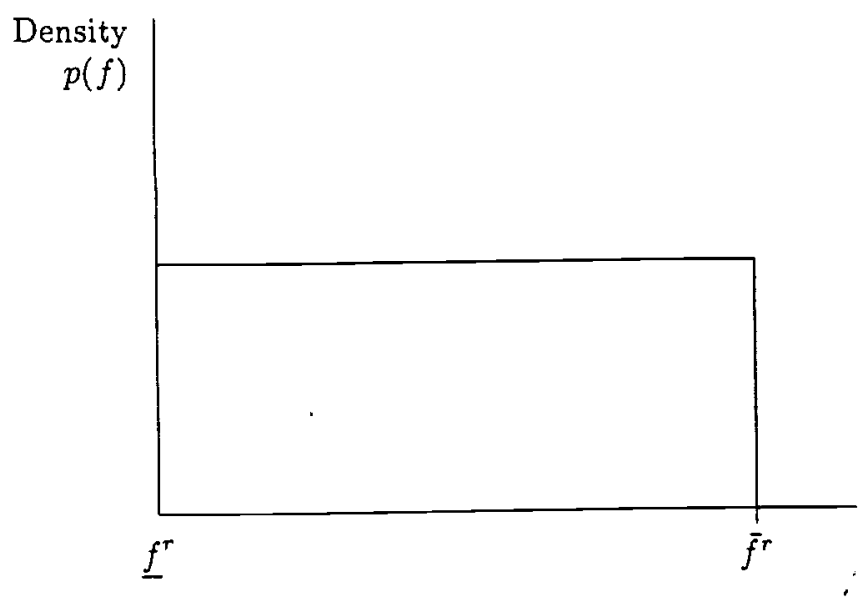

With No Intra-Band Intervention

FIGURE 3: Fundamentals Distribution Within a Target Band

$$
(\mu=0)
$$




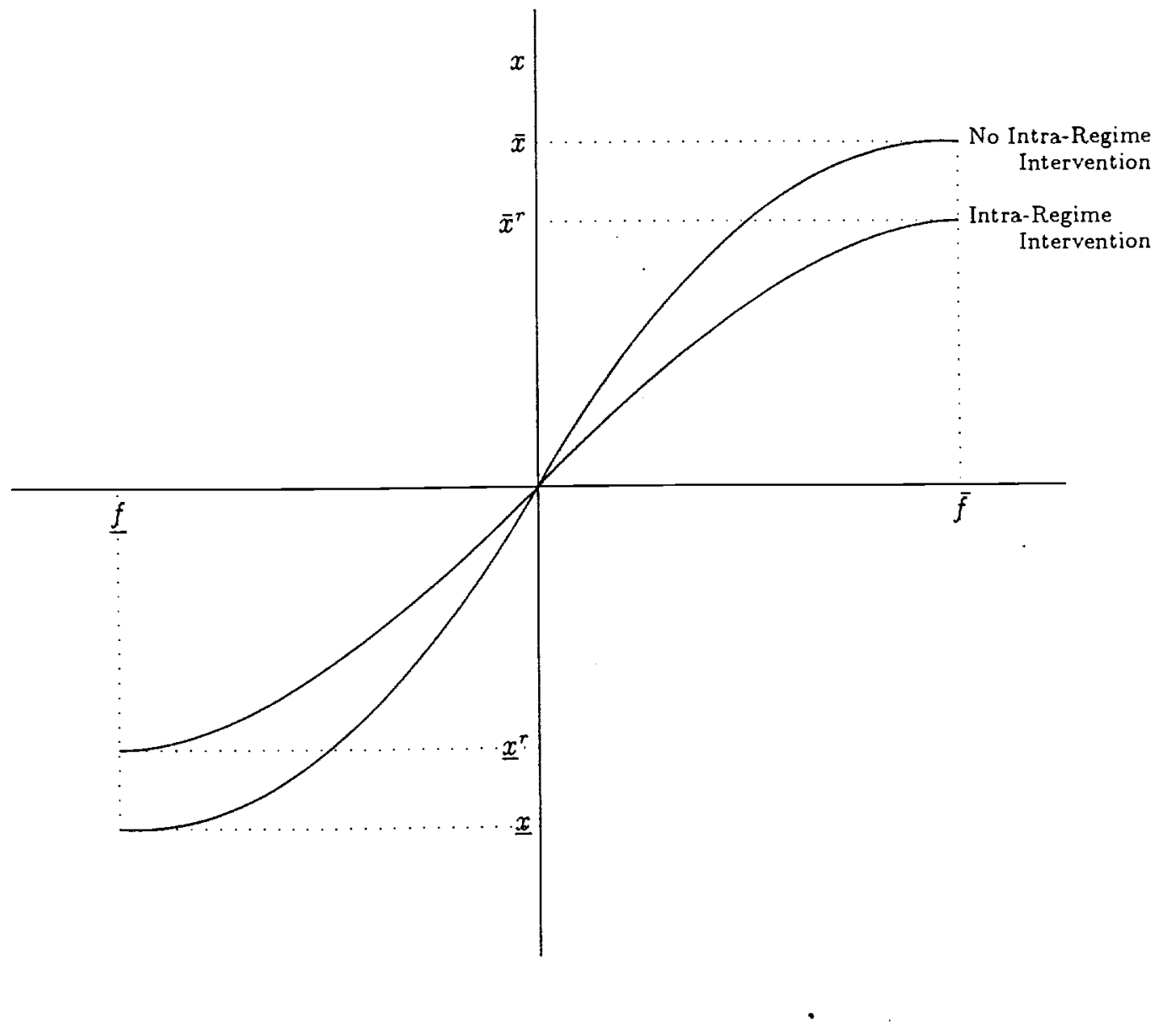

Figure 4: Exchange Rate Solutions for Target Band 


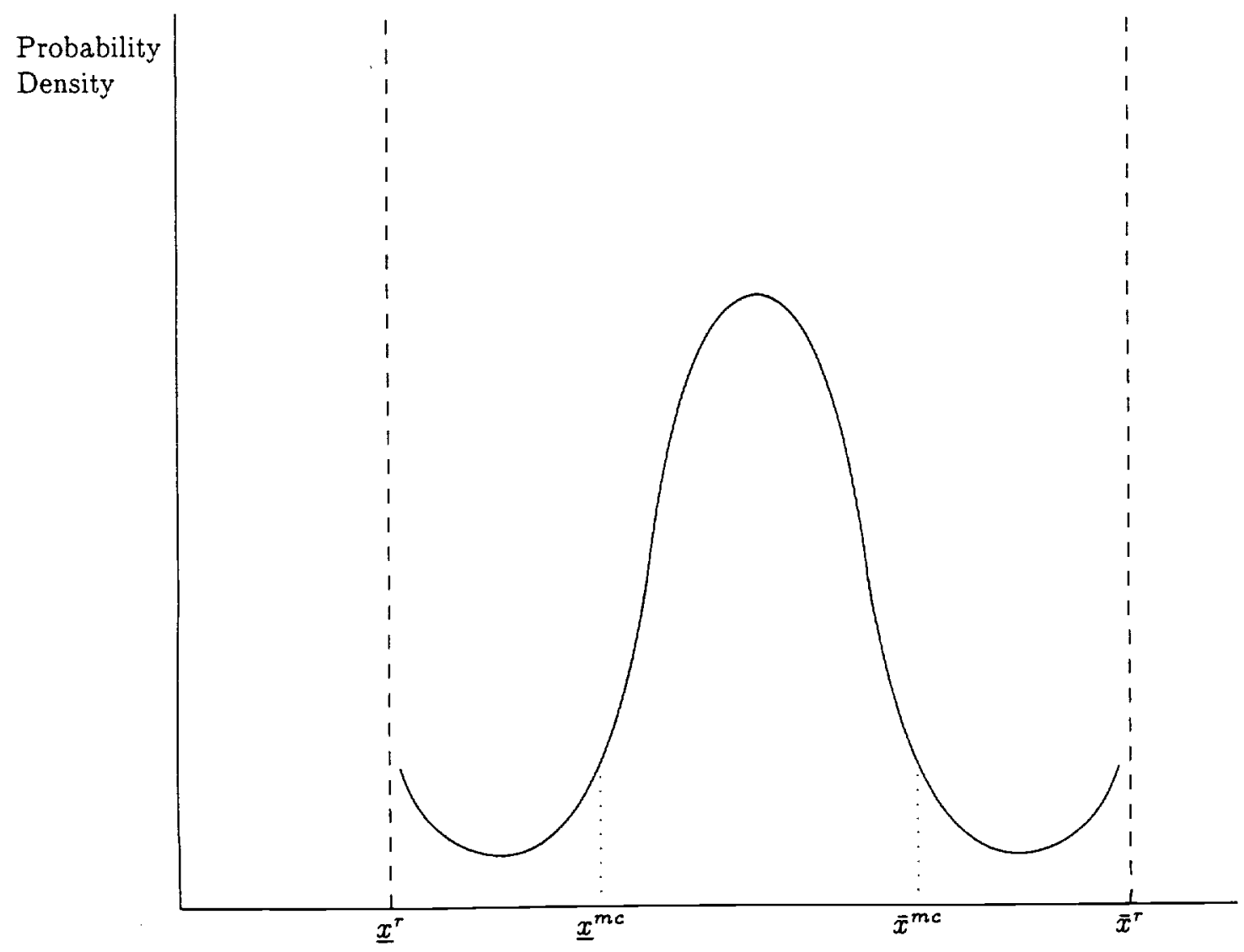

FIgURE 5: Distribution of Exchange Rates with Interventions within Target Bands 